\title{
Environmental Sustainability through Clothing Recycling
}

\author{
S. Cuc ${ }^{1}$ M. Vidovic ${ }^{2}$ \\ ${ }^{1}$ Faculty of textiles and leatherwork, University of Oradea, Romania \\ ${ }^{2}$ Faculty of transport and traffic engineering, University of Belgrade, Serbia \\ ${ }^{1}$ sunhilde_cuc@yahoo.com,gr, ${ }^{2}$ mvidovic@sf.bg.ac.rs
}

\begin{abstract}
This paper examines the process of achieving environmental sustainability through recycling of textile wastes. The recycling of textile waste can serve as a mean of providing solutions to many financial and environmental problems such as high cost of waste disposal and diminution of natural resources. The benefits and problems of this exercise are also highlighted. There are benefits to all three aspects that define sustainability: economical, social and environmental but there are also negative aspects too. The conclusion drawn is that the recycling of waste is of huge benefits especially in solving the numerous environmental problems and boosting the nation's economy. To quantify potential ecological benefits and economical effects of textiles waste recycling, the paper proposes modeling framework which makes trade off between costs of reverse network for textiles waste establishing and operating, and its effects on the virgin materials consumption, land use reduction, employment increase, and resold wearable textiles earnings.
\end{abstract}

Keywords: sustainable development, closed loop SCM modeling, textiles waste

\section{Recycling and Sustainable Development}

Sustainable development has become a constituent part of economic and environmental policy not only in developed country but also in many developing countries. Today's most burning environmental problems arise from ever increasing volumes of worldwide production and consumption and the associated material flows (UNEP, 2007). The supply of goods is always correlated to the use of natural resources, including raw materials (renewable and non-renewable), energy, water and land. The processes of accelerated population growth and urbanization translate into a greater volume of waste generated (Medina, 1997). Due to growth of world population, continued high levels of consumption special in the developed world, worldwide pressures on the environment issues are steadily increasing.

\footnotetext{
${ }^{*}$ Corresponding Author
}

The main aim of sustainability is to extract the maximum benefits from products by extending their life, before throwing them away. The economists and environmentalists studies on technical and economic requirement for sustainability revealed the need for increasing waste prevention and recycling. Here are a few reasons why recycling is important:

- Economical reasons: Recycling programs cost fewer than waste disposal programs; The high water, energy, manufacture consume makes it much cheaper to recycle than to produce some new textile products; Recycling can be financially rewarding, people can receive money for turning in certain recyclable products;

- Social reasons: Recycling creates jobs. Recycling centres create four jobs for every one job in the waste disposal industry (Shore 1995). The method can also give opportunities for small or family business. In USA the recycling and reuse industry 
sustained approximately 56,000 operations that employed over 1.1 million people, generated an annual payroll of nearly $\$ 37$ billion, and grossed over $\$ 236$ billion in annual revenues. The study also documented the "indirect" impact of recycling on support industries, such as accounting firms and office supply companies. It found that the reuse and recycling industry indirectly supports 1.4 million jobs that have a payroll of $\$ 52$ billion and produce $\$ 173$ billion in receipts (US 2001); Recycling builds community. People band together and build communities around environmental issue as a common cause.

- Environmental reasons: Conserves natural resources such as water (Rösch and Cuc, 2008), oil and natural gas (Hill and Holman 2001); Many countries and regions are already facing water scarcity today due to the excessive use of water for agricultural and industrial purposes; The extraction of water by humans has doubled since 1960 (WWF 2008); Saves energy because less energy is used to manufacture brand new products. Produces less greenhouse gases because industries burn fewer fossil fuels ( $\mathrm{CO}_{2}$ emissions); Prevents the destruction of natural habitats; From a sustainability perspective, a reduction in the total amount of land used for textile production is an important objective in order to prevent future conflicts related to land use.

\section{Textile recycling}

Textile industry is among the most essential consumer goods industry. Textiles products are usually classified according to their end market. The sector is divided into three major sub-sectors of activity which are characterised by different industry dynamics and success drivers. Therefore we can talk of apparel (fashion/design), interior textiles, and technical textiles. In Europe, each of these segments account, roughly, for $1 / 3$ of total market share (Euratex 2009).

The textile/clothing has a relevant place in the industrial landscape worldwide, both in terms of turnover and employment. It is the largest sub-sector of activity accounting for more than $37 \%$ of total European industrial activity (based on fibre utilisation), and is globally worth over $£ 500$ billion (Euratex, 2009), employing approximately 26 million people and supporting a significant number of economies and individual incomes around the world (DEFRA, 2009). This economic sub-sector has a significant adverse environmental and social impact across it global lifecycle - with rising consumption being a key factor in this. The Clothing and Textile industry accounts for an estimated 5 to $10 \%$ of all environmental impacts throughout the EU, so improving the environmental performance of the industry is vital (Ralph, 2009). The recycling of textile waste is not only an important means of solving the numerous environmental problems but also a means of socioeconomic and environmental sustainability.

Recycling is the method of reusing or reprocessing used clothing, fibrous material and clothing scraps from the manufacturing process. When considering textile recycling we must understand what the material consists of. Most textiles are composites of biodegradable materialsvegetal fibres (cotton, flax, hemp, jute, ramie, kenaf, flax, abaca), animal fibres (wool, catgut, sinew, silk, cashmere, mohair, angora), mineral fibres, wood fibre, man-made fibre (lyoccel, rayon, modal), (Koslowski, 2009) - and non biodegradable (typically composed of polypropylene, polyethylene, nylon or other synthetic fibbers). A particular problem in landfill as synthetic products is that it will not decompose, while woollen garments do decompose and produce methane, which contributes to global warming. With increasing concerns regarding the effect the textile industry is having on the environment, textile researchers (Blackburn, 2005), producers and manufacturers are looking to biodegradable and sustainable fibres as an effective way of reducing the impact textiles have on the environment. The textile's composition will affect its durability and method of recycling.

According to the Council for Textile Recycling, textile recycling material can be classified as pre or post consumer waste. Pre-consumer waste is arising during the manufacture of a product and post-consumer waste is "any type of garment or household article made from manufactured textiles that the owner no longer needs and decides to discard."(http://www.sewing-green.com/textilerecycling.html). Pre-consumer waste textiles consist of by-product materials from the textile, fibre and cotton industries. According to the Council for Textile Recycling, each year 750,000 tons of this waste 
is recycled into new raw materials for the automotive, furniture, mattress, coarse yarn, home furnishings, paper and other industries. Through the efforts of this industry approximately 75 per cent of the preconsumer textile waste that is generated is diverted from landfills and instead recycled (Darrel, 2007).

Post-consumer textile waste consists of any type of garments or household article, made of some manufactured textile that the owner no longer needs and decides to throw away. These articles are discarded either because they are worn out, damaged, outgrown, or out of style. They are sometimes given to charities or sold second hand, but more typically are disposed of into the trash and end up in municipal landfills. Over one million tonnes of textiles are discarded annually, mostly from domestic sources, of which $25 \%$ are recycled (Cupit, 1996) as outlined in Figure 1.

Figure 1. Destination of post-consumer textiles (Source: Textiles Recycling Association, published in A Way With Waste 1999)

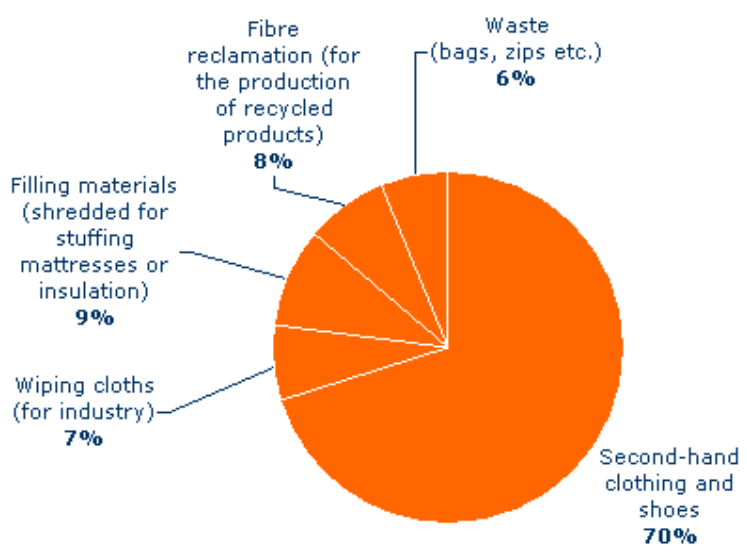

The recycling process involves three stages as it illustrated in Figure 2.

In the first stage the old textile products are collected and processed, where they are sorted, cleaned and made ready for recycling or manufacturing new products. Across Europe, an estimated 15 to $20 \%$ of potential existing tonnage is really collected. Germany and the UK on the one hand and Poland and Romania on the other hand are a few exceptions. Germany has an ecological tradition and collects roughly $70 \%$ of its potential tonnage and the
Figure 2. Textile Recycling Process

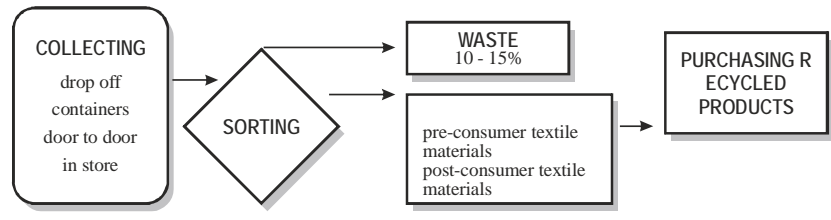

UK generates approximately 1.5 - 2 million tonnes per annum (2006) of clothing waste. Of this 63\% (1.2 million tonnes) enters the household waste stream going to landfill, $16 \%$ (300,000 tones) is recovered and $21 \%$ unaccounted for in what is assumed the "national wardrobe" (DEFRA, 2006). Poland and Romania are importers of textiles from western countries and has only taken its first hesitant steps toward collecting textiles for recycling.

A number of different systems have been implemented to collect material to be recycled from the general waste stream. These systems tend to lie along the spectrum of trade-off between public convenience and government simplicity and expense.

The main categories of textile collection are through drop-off centres, curbside collection, door to door collections and newest in store collection. Dropoff centres require the waste producer to carry the material to a central location, either an installed or mobile collection station or the reprocessing plant itself. They are the easiest type of collection to establish, but suffer from low and irregular throughput. The door to door collection method of garments is a successful method and is being prevalent in poor land from a long time.

All collected textiles are sorted and graded by experienced workers, who are able to recognise the large variety of fibre types resulting from the introduction of synthetics and blended fibre fabrics. Workers sort and separate collected textiles into good quality clothing and shoes which can be reused or damaged. Also, fibre reclamation mills sort textiles according to fibre type and colour. Colour sorting eliminates the need to re-dye the recycled textiles. There is a trend of moving these facilities from developed countries to developing countries either for charity or sold at a cheaper price. Once sorted the items are sent to various destinations as shown in Table 1. 
Table 1. Main destination of Textile Waste

\begin{tabular}{|c|c|c|c|}
\hline \multirow{2}{*}{ Wearable textiles } & \multicolumn{3}{|c|}{ Unwearable textiles } \\
\hline & Jeans, skirts, etc. & Woollen garments & Cotton and silk \\
\hline $\begin{array}{l}\text { Resold abroad in Asia, Africa and East } \\
\text { European countries. }\end{array}$ & $\begin{array}{l}\text { Sold to the 'flocking' industry. } \\
\text { ltems are shredded for fillers } \\
\text { in car insulation, roofing felts, } \\
\text { loudspeaker cones, panel } \\
\text { linings, furniture padding etc. }\end{array}$ & $\begin{array}{l}\text { Sold to specialist firms for fibre } \\
\text { reclamation to make yarn or } \\
\text { fabric. }\end{array}$ & $\begin{array}{l}\text { Sorted into grades to make } \\
\text { wiping cloths for a range of } \\
\text { industries from automotive to } \\
\text { mining, and for use in paper } \\
\text { manufacture }\end{array}$ \\
\hline
\end{tabular}

The second stage involves the manufacturing of new products from the raw material obtained by the processing of the old products. There are two ways of recycling pre-consumer textile materials; mechanically, where fibres are pulled apart and reworked into yarn, and chemically where fibres are repolymerized into a chemical and spun. Knitted or woven woolens and similar materials are "pulled" into a fibrous state for reuse by the textile industry in low-grade applications, such as car insulation or seat stuffing. The textiles are shredded and mix together with other selected fibres, depending on the intended end use of the recycled yarn. The blended mixture is carded to clean and mix the fibres and spun ready for weaving or knitting. The fibres can also be compressed for mattress production. Textiles sent to the flocking industry are shredded to make filling material for car insulation, roofing felts, loudspeaker cones, panel linings and furniture padding.
Finally, the process ends with the purchasing of recycled goods by the consumers at the top of reverse supply chain (production plants) and completes the recycling loop.

\section{Modeling framework for the textiles waste recycling effects estimation}

In order to quantify potential ecological and social benefits and economical effects of textiles waste recycling this paper proposes the LP optimization model of the closed loop supply chain network, shown in Figure 3.

Model is based on the assumption of an existing forward supply chain, operating on a market with known supply and demand, and reverse network that should be established. Hence, the main intention

Figure 3. Textiles closed loop supply chain network

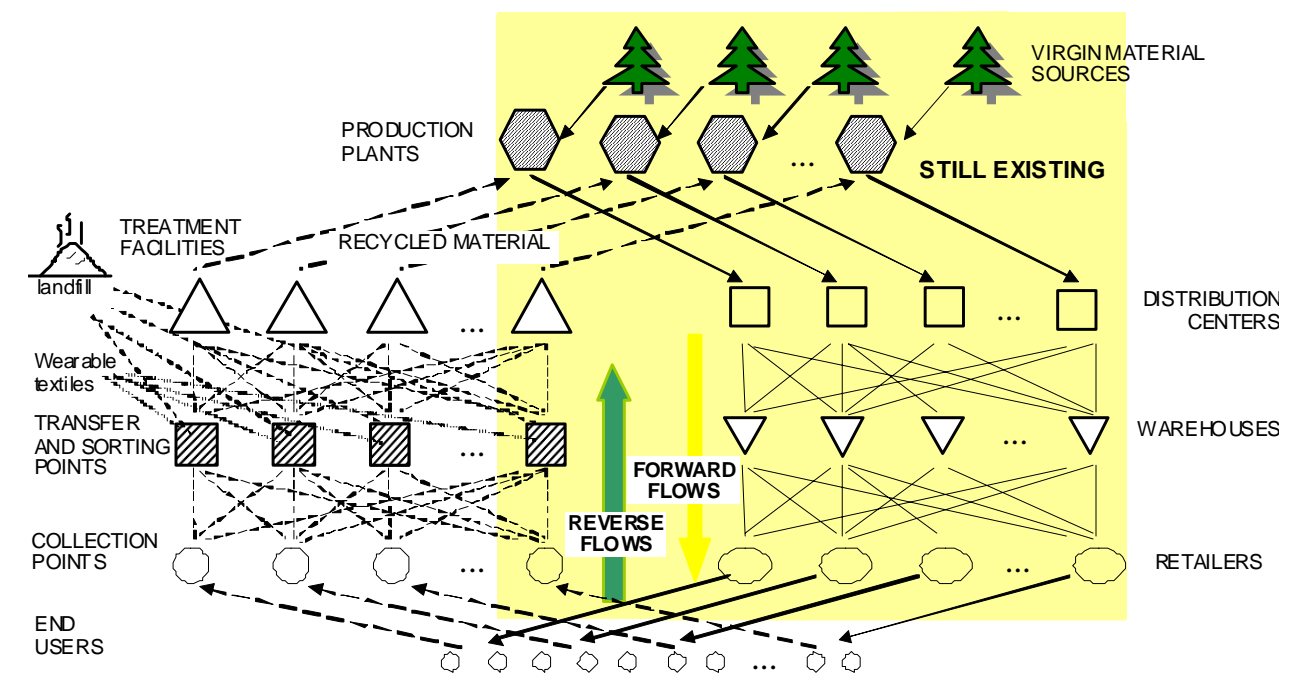


here is to analyze modelling approach that could be used to establish three level reverse logistics network for textile waste products, composed of a set of collection points, sorting points and recycling facilities, while respecting its impact on the virgin materials consumption, land use reduction, employment increase, and resold wearable textiles earnings, versus reverse network for textiles waste establishing and operating.

Most of the literature about reverse logistics network design considers various facility location models based on the MILP, and in many cases forward and reverse networks are modelled separately. Consequently, this leads to significant problem reduction, which is the case with this paper. However, there are only few researches related to problems in textiles recycling networks. In the research project (Prige et. al), the authors investigate economic and environmental benefits of product integrated environmental protection strategies. An example is given by the textile supply chain for wool. Very interesting chapter about carpet recycling can be found in Helms and Hervani (2006), where authors explore the issues of reverse logistics for recycling within the carpet industry, including an economic analysis of the success of carpet recycling. Paty et. al (2006) presents a linear optimization model for paper industry to compare total system cost of wood as a raw material with recycling of waste paper. Objective of the proposed model is to minimize the cost of paper in the supply chain. Vidovic and Ratkovic (2010) presents approach to establishing three level reverse logistics network for textiles recycling, introducing catchment area in order to model influence of distance between users and collection points on the network configuration.

In its main idea, facility location model proposed here is similar to the formulation of two-stage capacitated facility location problem (TSCFLP) described in Klose and Drexl (2005), but because of multilevel problem nature, different network structure and different objectives, mentioned approach has modified. In the proposed model formulation following notation has been used:

$i$ end user/owner of textile products (aggregated in larger units like buildings, schools,...)

$k$ collection point (drop - off location) which receives textile waste products from users

l sorting facility which receives textile waste from collection points $j \quad$ recycling facility which receives sorted textiles waste from sorting facilities

$C_{k l}$ costs of transporting textiles waste from collection point $k$ to sorting facility $l$

$C_{l j}$ costs of transporting textiles waste from sorting facility $l$ to recycling facility $j$

$C_{I J+1}$ costs of transporting textiles waste from sorting facility $l$ to second hand shop

$\mathrm{C}_{I J+2}$ costs of transporting textiles waste from sorting facility $l$ to the landfill site

$C_{j s}$ costs of transporting textiles waste from recycling facility $j$ to production plant $s$

$C_{v s}$ costs of transporting virgin sources raw material from source $v$ to production plant $s$

$X_{i k}$ fraction of textile waste from user $i$ collected at collection point $k$

$X_{k l}$ fraction of textile waste from collection point $k$ transported to sorting facility $l$

$X_{l j}$ fraction of textile waste from sorting facility $l$ transported to recycling facility $j$

$X_{I J+1}$ fraction of textile waste from sorting facility $l$ transported to second hand shop

$X_{I J+2}$ fraction of textile waste from sorting facility $l$ transported to the landfill site

$X_{j s}$ fraction of textile waste from recycling facility $j$ to production plant $s$

$Q_{v s}$ quantity of virgin sources raw material from source $v$ to production plant $s$

$G_{k}, G_{l}, G_{j}, G_{s}$ capacities of collection $k$, sorting $l$, recycling $j$, and production facility, resp.

$f_{k}, f_{l}, f_{j}$ costs of opening collection, sorting and recycling facilities at locations $k, l, j$ respectively (including financial equivalent of land use)

$Y_{k}, Y_{l}, Y_{j}$ binary variables, equals 1 when collection, sorting or recycling sites are opened, otherwise equals 0

$\alpha$ fraction of wearable textile waste that can be resold and directly reuse $0 \leq \alpha \leq 1$

$\beta$ fraction of sorted textile waste that will be land filled $0 \leq \beta \leq 1$

$\psi$ financial equivalent of preserving unit quantity of virgin resources

$\lambda$ earnings from resoling unit quantity of textile waste that can be directly reused

$\rho$ financial equivalent of land use reduction per unit quantity of textiles waste

$\varepsilon \quad$ financial equivalent of employment increase per unit quantity of recycled textiles 
Proposed multilevel MIP model of reverse logistics network for textile waste, composed of a set of collection points, sorting and recycling facilities, which respects sustainability criterions is presented below.

$$
\begin{aligned}
& \sum_{\mathrm{k}} \sum_{\mathrm{l}} \mathrm{C}_{\mathrm{kl}} \mathrm{X}_{\mathrm{kl}}+\sum_{\mathrm{l}} \sum_{\mathrm{j}} \mathrm{C}_{\mathrm{lj}} \mathrm{X}_{\mathrm{lj}}+\sum_{\mathrm{l}}\left(\mathrm{C}_{\mathrm{lj}+1} \mathrm{X}_{\mathrm{lj}+1}+\mathrm{C}_{\mathrm{lj}+2} \mathrm{X}_{\mathrm{lj}+2)}+\right. \\
& \sum_{\mathrm{j}} \sum_{\mathrm{s}} \mathrm{C}_{\mathrm{js}} \mathrm{X}_{\mathrm{js}}+\sum_{\mathrm{k}} \mathrm{f}_{\mathrm{k}} \mathrm{Y}_{\mathrm{k}}+\sum_{\mathrm{l}} \mathrm{f}_{1} \mathrm{Y}_{1}+\sum_{\mathrm{j}} \mathrm{f}_{\mathrm{j}} \mathrm{Y}_{\mathrm{j}}+ \\
& \sum_{\mathrm{v}} \sum_{\mathrm{s}} \mathrm{C}_{\mathrm{vs}}\left(\mathrm{Q}_{\mathrm{vs}}-\sum_{\mathrm{j}} \mathrm{X}_{\mathrm{js}}\right)-\psi \sum_{\mathrm{j}} \sum_{\mathrm{s}} \mathrm{X}_{\mathrm{js}}-\lambda \sum_{1} \mathrm{X}_{1 \mathrm{j}+1}{ }^{-} \\
& \left.\rho\left(\sum_{\mathrm{i}} \mathrm{q}_{\mathrm{i}}-\sum_{1} \mathrm{X}_{\mathrm{lj}+2}\right)-\varepsilon \sum_{\mathrm{k}} \sum_{\mathrm{l}} \mathrm{X}_{\mathrm{kl}}+\sum_{\mathrm{l}} \sum_{\mathrm{j}} \mathrm{X}_{\mathrm{lj}}\right) \\
& \text { s.t } \\
& \sum_{\mathrm{k}} \mathrm{X}_{\mathrm{ik}}=\mathrm{q}_{\mathrm{i}} \quad \forall \mathrm{i} \\
& \sum_{\mathrm{i}} \mathrm{X}_{\mathrm{ik}}-\sum_{\mathrm{l}} \mathrm{X}_{\mathrm{kl}}=0 \quad \forall \mathrm{k} \\
& \sum_{\mathrm{k}} \mathrm{X}_{\mathrm{kl}}-(1-\alpha-\beta) \sum_{\mathrm{j}} \mathrm{X}_{\mathrm{lj}}-\mathrm{X}_{\mathrm{lj}+1}-\mathrm{X}_{\mathrm{lj}+2}=0 \quad \forall 1 \\
& \sum_{\mathrm{l}} \mathrm{X}_{\mathrm{lj}}-\sum_{\mathrm{s}} \mathrm{X}_{\mathrm{js}}=0 \quad \forall \mathrm{j} \\
& \mathrm{X}_{\mathrm{ik}} \leq \mathrm{Y}_{\mathrm{k}} \mathrm{G}_{\mathrm{K}} \quad \forall \mathrm{i} \text {, } \\
& \text { k } \\
& \mathrm{X}_{\mathrm{kl}} \leq \mathrm{Y}_{1} \mathrm{G}_{1} \quad \forall \mathrm{k}, 1 \\
& \mathrm{X}_{\mathrm{lj}} \leq \mathrm{Y}_{\mathrm{j}} \mathrm{G}_{\mathrm{j}} \quad \forall 1, \mathrm{j} \\
& \sum \mathrm{X}_{\mathrm{ik}} \leq \mathrm{G}_{\mathrm{k}} \quad \forall \mathrm{k} \\
& \sum \mathrm{X}_{\mathrm{kl}} \leq \mathrm{G}_{\mathrm{l}} \quad \forall 1 \\
& \sum \mathrm{X}_{\mathrm{lj}} \leq \mathrm{G}_{\mathrm{j}} \quad \forall \mathrm{j} \\
& \sum \mathrm{X}_{\mathrm{js}} \leq \mathrm{G}_{\mathrm{s}} \quad \forall \mathrm{s} \\
& \mathrm{Y}_{\mathrm{k}} \in(0,1), \mathrm{Y}_{\mathrm{i}} \in(0,1), \mathrm{Y}_{\mathrm{j}} \in(0,1) \\
& \mathrm{X}_{\mathrm{ik}}, \mathrm{X}_{\mathrm{kl}}, \mathrm{X}_{\mathrm{ij}}, \mathrm{X}_{\mathrm{ij}+1}, \mathrm{X}_{\mathrm{ij}+2}, \mathrm{X}_{\mathrm{js}} \geq 0
\end{aligned}
$$

\section{Minimize :}

The objective function (1) minimizes the sum of reverse network for textiles recycling costs, and its effects on the virgin materials consumption, land use reduction, employment increase, and earnings from wearable textiles. Note that because objective function should be minimized, positive effects of network establishing are included as negative values that are subtracted from costs. All the supply of textile waste available at the users site is defined by constraint set (2). Equalities set (3), (4), (5) represent flow conservation constraints. Constraints sets (6), (7), (8) prohibit units from being routed through collection, sorting and recycling sites unless the site is opened. Constraint set (9), (10), (11), (12) limit the quantities sent to the collection, sorting, recycling and production sites up to the capacity of those sites. Constraint sets (13), (14) enforce the domain of decision variables.

\section{Conclusion}

There are benefits to all three aspects that define sustainability: economical, social and environmental but there are also negative aspects too. One of the problems is that the used textile imported (especially second hand clothes) by poor or developing countries can lead to an economic decline in that sector.

Governments, as well as businesses and individual consumers, each play an important role in making the recycling process a success. Government intervention may mean that new valueadded recycling technologies enter the market, and therefore the average system will change. If recycling technologies improved, then recycling could be as or even more worthwhile than reuse, particularly if the systems become closed loop. Recycling of textiles presents several promising technologies and ideas for recycling systems. It is useful to settle on the far-off prospects of material use for an environmentally sustainable economy. The motivation for waste and pollution prevention through recycling can only be fully appreciated when related to long-run goal of material conservation.

Effects of textile recycling on sustainable development is modelled as MIP model with the objective of analyzing trade off between costs of reverse network for textiles waste and its effects on 
the virgin materials consumption, land use reduction, employment increase, and earnings from wearable textiles. Model application and adjusting is left for the future research.

\section{References}

Blackburn, R.S.,( 2005), Biodegradable and sustainable fibres, Woodhead Textiles Series No. 47, Frank, E.N., Hick, M.V.H. and Adot, O. (2007). Descriptive differential attributes of type of fleeces in Llama fiber and its textile consequence. 1-Descriptive aspects. The Journal of the Textile Institute 98: (3): 251-259.

Cupit M.J., (1996), Opportunities and Barriers to Textile Recycling, AEA Technology, May.

Darrel R., (2007), Post-consumer waste and Pre-consumer waste : What exactly is the difference?, available on the Web at http://www.amazines.com/ article_detail.cfm?articleid=363930.

DEFRA, (2006), Environmental Expenditure \& Wildlife Statistics data.

DEFRA, (2009), Sustainable Clothing Action Plan, Department for Environment, Food and Rural Affairs, London.

Euratex (2009), The EU-27 Textile \& Clothing Industry in the year 2008 - General assembly 5th of June 2009; Roberta Adinolfi available on the Web at www.euratex.org/download/research/publications/ euratex-netfintex_brochure.pdf accessed 10.06.2010

Helms M. M., Hervani A. A., (2006), Reverse Logistics for Recycling: Challenges Facing the Carpet Industry, Book chapter in Greening the Supply Chain, Joseph Sarkis, Springer.

Hill, G. and Holman J., (2001), Chemistry in Context. 5th Edn., Thomas Nelson and Sons, London.

http://www.sewing-green.com/textile-recycling.html.

Klose A., Drexl A. (2005), Facility location models for distribution system design, European Journal of Operational Research, 162, pp. 4-29

Koslowski. H.-J., (2009), Dictionary of Man-made fibers. Second edition. Deutscher Fachverlag.
Medina, M., (1997), The Effect of Income on Municipal Solid Waste Generation Rates for Countries of Varying Levels of Economic Development: A Model. Journal of Solid Waste Technology \& Management, August: 149-55

Pati, R. K, Vrat, P., Kumar P., (2006), Economic analysis of paper recycling vis-a-vis wood as raw material, Int. J. Production Economics, 103, pp. 489-508

Prigge V., Siestrup G., Förster M., Haasis H.D., Product Integrated Environmental Protection Strategies in the Textile Supply Chain: Source of Economic and Environmental Benefits, University of Bremen, available on the Web at http://www.pro.wiwi.uni-bremen.de

Ralph T., President of Textile Recycling Association, (2009), available on the Web at http://www.defra.gov.uk/ environment/business/products/roadmaps/ stakeholder-quotes.htm accessed 10.06.2010

Rösch, H., Cuc, S., (2008), Abwasserrecycling in der Textilveredelungsindustrie. The International Scientific Symposium "Innovative Solutions For sustainable Development Of Textiles Industry". Annals of the Oradea University, Fascicle of of Textiles and Leatherwork. Vol. IX. Edit. University of Oradea.

Shore M., (1995), The Impact of Recycling on Jobs in North Carolina, NC Recycling Business Assistance Center, Raleigh, North Carolina, July 1-1.

U.S. Recycling Economic Information Study, (2001), prepared by RW Beck for the National Recycling Coalition, available on the Web at: http://www.epa.gov/ waste/conserve/rrr/rmd/rei-rw/index.htm, accessed 10.06.2010

UNEP. (2007), Global Environmental Outlook 4, United Nations Environment Programme, Nairobi.

Vidovic, M., B. Ratkovic (2010), A multi-level approach to sitting textiles waste treatment resources, Annals of the Oradea University. "Fascicle Of Textile- Leatherwork", issued in Proceedings on CD-ROM of International Scientific Conference "Innovative solutions for sustainable development of textiles industry", Oradea Romania, 28-30 May 2010, Vol. I, No.2, pp 246-252

WWF, (2008), Zoological Society of London, Global Footprint Network. (2008). Living Planet Report 2008. WWF, Gland, Switzerland.

Sunhilde Cuc is Lecturer at the Faculty of Textiles and Leatherworks of the University of Oradea, Romania. She gained a Diploma in Mechanical Engineering from the Technical University Cluj Napoca and completed a PhD at the same institution. She received also a Diploma in Finance and Insurance from the University of Oradea. Her academic work has focussed recently on Supply Chain and Reverse Logistics Management in Textile Industry. Other work includes corporate sustainability, environmental and ethic issues. She has published over 50 papers in leading academic journals and international conferences' proceedings. Sunhilde Cuc is member of Organizing Comitee of the International Scientific Conference "Innovative solutions for sustainable development of textiles industry". She is member of the General Association of Engineers in Romania (AGIR) and the Association of Managers and Engineer-Economists in Romania (AMIER). 
Milorad Vidovic was born in Belgrade, Serbia in 1957, where he finished elementary and high school. He graduated from the University of Belgrade, at Faculty of transport and traffic engineering, where took PhD dissertation in 1998. He works at the same University, at Logistics department since 1987. Since December 2005 he became associate professor at Logistics department, teaching courses in "Materials handling", "Simulation of logistic systems" and "Reverse logistics" on undergraduate level. At the master level studies he teaches courses "Operational planning of material handling processes", and "Advance topics in reverse logistics". On PhD studies he teaches courses "Supply chains", and "Material handling systems". During years 2000 and 2001 he worked as visiting assistant professor at Pusan National University, Busan South Korea and Korean advanced institute of science and technology in Daejeon, South Korea. From 2004 to 2008 was engaged as visiting professor at Logistics department of Izmir University of economy, Izmir, Turkey. His research interest is related to modeling and application of quantitative and operations research methods in logistics. He participated and conducted numerous research projects, supervised several master and PhD thesis, and is author of two books and more than 80 papers published in journals and conference proceedings. 